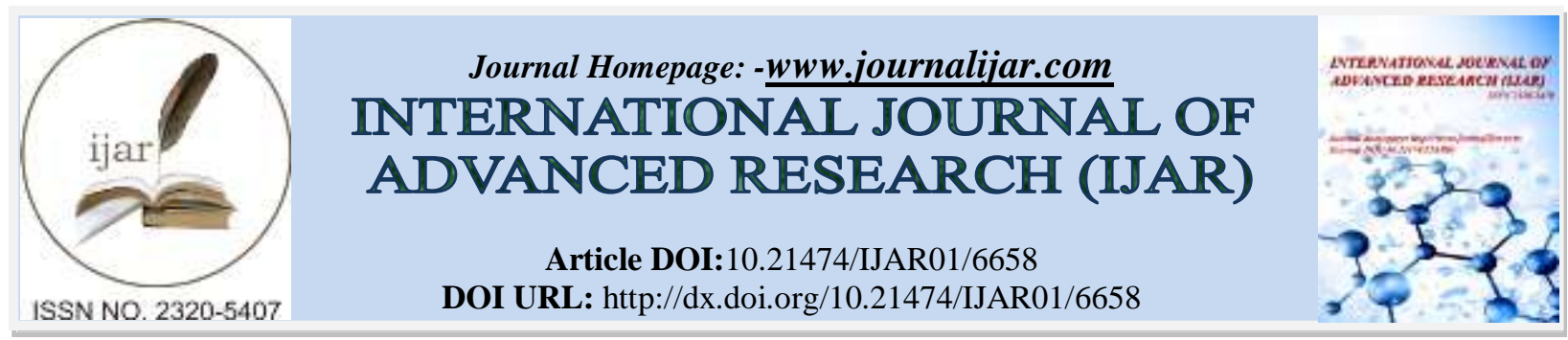

RESEARCH ARTICLE

\title{
COMPARISON OF FORMOTEROL-BUDESONIDE FORMULATION NEBULIZED ALONE AND IN COMBINATION WITH IPRATROPIUM BROMIDE FORMULATION IN PATIENTS WITH CHRONIC OBSTRUCTIVE PULMONARY DISEASE.
}

Juhi Singla ${ }^{1}$, S C Chopra ${ }^{1}$, D P S Sudan ${ }^{2}$, Shweta Sharma ${ }^{1}$, Naveen Kumar ${ }^{3}$ and Vinod Kapoor ${ }^{1}$.

1. Department of Pharmacology, SGT Medical College, Hospital and Research Institute, Gurugram, Haryana.

2. Department of Pulmonary Medicine, SGT Medical College, Hospital and Research Institute, Gurugram, Haryana.

3. Department of Pharmacology, Shaheed Hasan Khan Mewati Government Medical College, Nalhar, Mewat, Haryana.

\section{Manuscript Info}

[.........................

Manuscript History

Received: 03 January 2018

Final Accepted: 05 February 2018

Published: March 2018

Keywords:-

Triple therapy, COPD, Spirometry, Formoterol-Budesonide, Ipratropium bromide.

\section{Abstract}

Background: Chronic Obstructive Pulmonary Disease (COPD) is a clinical syndrome associated with gradually progressive narrowing of the airways due to inflammation. The syndrome includes Bronchitis, Emphysema and small airway disease with common symptoms due to inflammation and chronic airflow obstruction.

Methods: COPD patients aged 40 years or more were allocated in two treatment groups. Group 1 was nebulized with Formoterol- Budesonide formulation (double drug) and Group 2 with Formoterol-Budesonide formulation along with Ipratropium bromide formulation (triple drug). Spirometry parameters were recorded at baseline and thirty minutes after nebulization.

Results: Within half an hour after nebulization, there was a statistically significant increase in all the Spirometry parameters in both the groups. The increase was slightly more in triple drug group $(n=26)$. The mean difference in the pre \& post-nebulization parameters was taken and it was found that only PEFR had statistically significant increase postnebulization. All Spirometry parameters increase was similar in both the groups.

Conclusions: The results of triple drug combination were slightly better (group 2). Mean change in the nebulization parameters showed statistically significant increase in PEFR in group 2.

Copy Right, IJAR, 2018,. All rights reserved.

\section{Introduction:-}

Chronic Obstructive Pulmonary Disease (COPD) is a major health hazard. It is a clinical syndrome associated with gradually progressive narrowing of the airways due to inflammation. COPD includes Bronchitis, Emphysema and small airway disease with common symptoms due to inflammation and chronic airflow obstruction. Cigarette smoking \& pollution due to vehicles, construction, industries, deforestation, lack of sufficient rain is the main cause of COPD. ${ }^{1}$ 
Inhalation route is the preferred mode of delivery of many drugs with a direct effect on airways. It is the preferred way to deliver some drugs such as cromolyn sodium, anticholinergics, $\beta_{2}$-agonist and corticosteroids to reduce systemic side effects. The major advantage of inhalation is the delivery of drugs to the airways in doses that are effective with a much lower risk of systemic side effects. ${ }^{2}$

In Chronic obstructive pulmonary disease, LABAs are effective bronchodilators that may be used alone or in combination with anticholinergics or Inhaled Corticosteroids (ICS). LABA improve symptoms as well as exercise tolerance by reducing both air trapping and exacerbations. ${ }^{2}$

The combination therapy is more convenient for patients. It also simplifies treatment and improves compliance with ICS because the patients perceive clinical benefit. There may be an additional advantage because delivering two or more drugs in the same inhaler ensures that they are delivered simultaneously to the same cells in the airways. It allows the beneficial molecular interactions between the drugs like LABA and corticosteroids to occur. A combination inhaler that contains Formoterol and Budesonide has shown to be more effective for relieving acute symptoms than either Terbutaline or Formoterol alone, suggesting that the inhaled corticosteroids may also be contributing to the benefit. ${ }^{2,4}$

In COPD, anticholinergics may be as effective as or even superior to $\beta_{2}$-agonists. They have relatively greater effect in COPD than in asthma. It may be explained by an inhibitory effect on vagal tone, which although not necessarily increased in COPD. It might be the only reversible element of airway obstruction and one that is exaggerated by geometric factors in the narrowed airways of COPD patients. Combination therapy of an anticholinergics and $\beta_{2^{-}}$ agonist are popular particularly among physicians treating COPD. Several studies have demonstrated additive

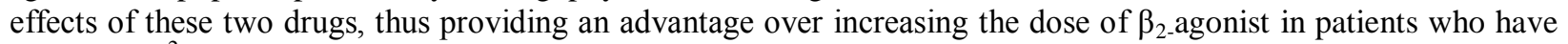
side effects. ${ }^{2}$

From this study we would like to know that whether there is any additional benefit of adding anticholinergics in terms of improvement in symptoms and spirometry parameters to well established double drug combination therapy i.e. LABA \& ICS combination in patients with COPD.

Only few studies have been done in this regard. Beneficial effects of steroids and $\beta_{2}$-agonist are known in COPD. Anticholinergics may be of great value when patient has lot of expectoration which is not controlled by other measures. This study therefore intends to measure the additional effect of adding anticholinergics (Ipratropium bromide) to LABA \& ICS (Formoterol-Budesonide) combination.

Hence, there are a lot of controversies regarding treatment regimen and mode of delivery in patients with COPD. A few studies were done in Indian scenario especially in the rural area where the smoke emitted is mainly due to smoky kitchens, more hookah \& beedi smokers and burning of agricultural biomass residue whereas in urban areas emitted smoke is due to pollution caused by vehicles, construction, industries etc.

This study was therefore planned to compare double drug nebulized therapy with the triple therapy in rural population of our country in the setting of more number of smoky kitchens, tobacco, hookah \& beedi smokers.

\section{Methods:-}

It was a prospective, interventional, open-label, hospital-based randomized study, conducted in the Department of Pulmonary Medicine, Faculty of Medicine and Health Sciences, SGT University, Budhera (now renamed as SGT Medical College, Hospital and Research Institute, SGT University), Gurgaon (now renamed as Gurugram), Haryana-122505 for a period of one year after obtaining approval from the Institution Thesis Committee and the Institution Ethics Committee. The study was registered in Clinical Trial Registry of India vide letter number CTRI/2017/09/009901). Informed written consent was recorded from the subjects.

COPD patients aged 40 years or more, after detailed history, clinical examination and necessary investigations, were randomly allocated to receive either Formoterol-Budesonide formulation (Group 1, n =29) or either FormoterolBudesonide \& Ipratropium bromide formulation (Group 2, n =26). 
All the patients were re-evaluated thirty minutes post-nebulization. Data was collected on separate Performa for every patient and was analyzed using MS Excel version 2007. p value of less than 0.05 was considered to be statistically significant.

\section{Results:-}

A total of 55 patients were included in this study. Out of these, 29 patients were included in Group 1 (FormoterolBudesonide) and 26 patients were included in Group 2 (Formoterol-Budesonide \& Ipratropium bromide).

Table 1 provide the intergroup comparison of the age group, Gender, BMI, QoL score, history of exacerbation and Clinical symptoms by Chi-square test. There was no significant difference in both the groups.

Pre and post-nebulization vitals were compared in between group $1 \& 2$ using paired t test as depicted in Table 2 . Heart Rate (HR) was increased post-nebulization in both the groups. Though, it achieved statistical significance only in group $2(\mathrm{p}=0.04)$. On the other hand, in group 1 , the rise in heart rate was not statistically significant $(\mathrm{p}=0.73)$. There was a statistically significant increase in oxygen saturation in both the groups.

There was statistically significant rise in SBP, DBP and MAP post-nebulization in group 1 as compared to baseline. While in group 2, there was no statistically significant increase in blood pressure as shown in Table 2.

Spirometry parameters were compared pre \& post-nebulization in between group $1 \& 2$ using paired t test. There was statistically significant increase post-nebulization in all the Spirometry parameters in both the groups. The increase was slightly more in group 2 as shown in table 3.

As shown in figure 1, the mean increase in Spirometry parameters was evaluated using unpaired t test. The mean difference in the pre \& post-nebulization parameters was taken and it was found that only PEFR had statistically significant increase post-nebulization. Rest all Spirometry parameters increase was almost same in both the groups. Post-nebulization clinical assessment of outcome was done by questioning the patient. It was found that in group 2 , majority of the patients i.e. $23(88.46 \%)$ stated clinical outcome of given treatment as better. While in group 1, the score was 19 i.e. $65.51 \%$ patients were feeling better post-nebulization.

Table 1:- Baseline Characteristics of patients in Group $1 \& 2$

\begin{tabular}{|c|c|c|c|}
\hline & $\begin{array}{l}\text { Group 1: } \mathrm{F}+\mathrm{B} \\
(\mathrm{n}=29)\end{array}$ & $\begin{array}{l}\text { Group 2: } F+B+I \\
(n=26)\end{array}$ & p value \\
\hline $\begin{array}{l}\text { Age Group } \\
40-50 \\
50-60 \\
60-70 \\
70-80 \\
80-90\end{array}$ & $\begin{array}{l}3(10.34 \%) \\
5(17.24 \%) \\
16(55.17 \%) \\
4(13.79 \%) \\
1(3.44 \%)\end{array}$ & $\begin{array}{l}4(15.38 \%) \\
2(7.69 \%) \\
10(38.46 \%) \\
5(19.23 \%) \\
5(19.23 \%)\end{array}$ & 0.24 \\
\hline $\begin{array}{l}\text { Gender } \\
\text { Female } \\
\text { Male }\end{array}$ & $\begin{array}{l}9(31.03 \%) \\
20(68.96 \%)\end{array}$ & $\begin{array}{l}4(15.38 \%) \\
22(84.61 \%)\end{array}$ & 0.17 \\
\hline$\frac{\text { BMI }}{\text { Mean }} \pm$ SD & $19.99 \pm 4.90$ & $18.44 \pm 5.03$ & 0.25 \\
\hline Warehouse worker & $1(3.44 \%)$ & $3(11.53 \%)$ & - \\
\hline $\begin{array}{l}\text { History of Exacerbation } \\
\text { Treated with Antibiotics } \\
\text { Treated with Steroids }\end{array}$ & $\begin{array}{l}14(48.27 \%) \\
13(44.82 \%) \\
6(20.68 \%)\end{array}$ & $\begin{array}{l}14(53.84 \%) \\
14(53.84 \%) \\
7(26.92 \%)\end{array}$ & 0.97 \\
\hline $\begin{array}{l}\text { QOL Score } \\
10-20 \\
21-30 \\
31-40\end{array}$ & $\begin{array}{l}3(10.34 \%) \\
19(65.51 \%) \\
7(24.13 \%)\end{array}$ & $\begin{array}{l}4(15.38 \%) \\
12(46.15 \%) \\
10(38.46 \%)\end{array}$ & 0.35 \\
\hline $\begin{array}{l}\text { Symptoms } \\
\text { Cough } \\
\text { Phlegm }\end{array}$ & $\begin{array}{l}27(93.1 \%) \\
24(82.75 \%)\end{array}$ & $\begin{array}{l}26(100 \%) \\
21(80.76 \%)\end{array}$ & \\
\hline
\end{tabular}




\begin{tabular}{|c|l|l|l|}
\hline $\begin{array}{l}\text { Wheezing } \\
\text { Dyspnoea }\end{array}$ & $15(51.72 \%)$ & $16(61.53 \%)$ & \\
$>$ Grade 1 & $1(3.44 \%)$ & $0(0 \%)$ & 0.86 \\
$>$ Grade 2 & $1(3.44 \%)$ & $2(7.69 \%)$ & \\
$>$ Grade 3 & $9(31.03 \%)$ & $11(26.92 \%)$ & \\
$>$ Grade 4 & $15(51.72 \%)$ & $6(23.07 \%)$ & \\
$>$ Grade 5 & $3(10.34 \%)$ & \\
\hline
\end{tabular}

Table 2:- Comparison of Vitals before and after Nebulization in Group $1 \& 2$

\begin{tabular}{|c|c|c|c|c|c|c|}
\hline Vitals & \multicolumn{3}{|l|}{$\mathbf{F + B}$} & \multicolumn{3}{|l|}{$\mathbf{F}+\mathbf{B}+\mathbf{I}$} \\
\hline & Before & After & p-value & Before & After & p-value \\
\hline HR & $91.68 \pm 13.47$ & $92.31 \pm 7.57$ & 0.73 & $91.5 \pm 13.16$ & $95 \pm 13.25$ & 0.04 \\
\hline SBP & $124.34 \pm 15.74$ & $128.41 \pm 14.50$ & 0.009 & $134.92 \pm 18.64$ & $135 \pm 18.38$ & 0.96 \\
\hline DBP & $79.93 \pm 10.52$ & $85.86 \pm 8.41$ & 0.0001 & $85.15 \pm 15.92$ & $87.92 \pm 11.89$ & 0.24 \\
\hline MAP & $94.73 \pm 11.15$ & $100.04 \pm 8.87$ & 0.0001 & $101.74 \pm 15.72$ & $103.61 \pm 12.85$ & 0.33 \\
\hline O2 Sat \% & $90.51 \pm 4.81$ & $95.55 \pm 3.39$ & $<0.0001$ & $90.19 \pm 3.16$ & $96.26 \pm 2.29$ & $<0.0001$ \\
\hline
\end{tabular}

Table 3:- Comparison of Spirometry parameters before and after Nebulization in Group $1 \& 2$

\begin{tabular}{|l|l|l|l|l|l|l|}
\hline $\begin{array}{l}\text { Spirometry } \\
\text { parameters }\end{array}$ & \multicolumn{2}{|l|}{$\mathbf{F + B}$} & \multicolumn{2}{l|}{ F+B+I } \\
\hline & Before & After & p-value & Before & After & p-value \\
\hline PEFR & $28.41 \pm 9.73$ & $37.33 \pm 10.98$ & $<\mathbf{0 . 0 0 0 1}$ & $27.40 \pm 12.74$ & $39.89 \pm 13.74$ & $<\mathbf{0 . 0 0 0 1}$ \\
\hline FEV1 & $46.02 \pm 17.35$ & $56.64 \pm 20.12$ & $<\mathbf{0 . 0 0 0 1}$ & $44.57 \pm 18.75$ & $57.82 \pm 20.30$ & $<\mathbf{0 . 0 0 0 1}$ \\
\hline FVC & $48.59 \pm 17.28$ & $59.68 \pm 18.72$ & $\mathbf{= 0 . 0 0 0 1}$ & $48.65 \pm 18.39$ & $60.48 \pm 18.47$ & $<\mathbf{0 . 0 0 0 1}$ \\
\hline FEV1/FVC & $73.20 \pm 21.45$ & $80.38 \pm 19.33$ & $\mathbf{= 0 . 0 0 1}$ & $70.42 \pm 19.44$ & $81.05 \pm 18.81$ & $<\mathbf{0 . 0 0 0 1}$ \\
\hline
\end{tabular}

Figure 1:- Mean increase in the spirometry parameters before and after nebulization

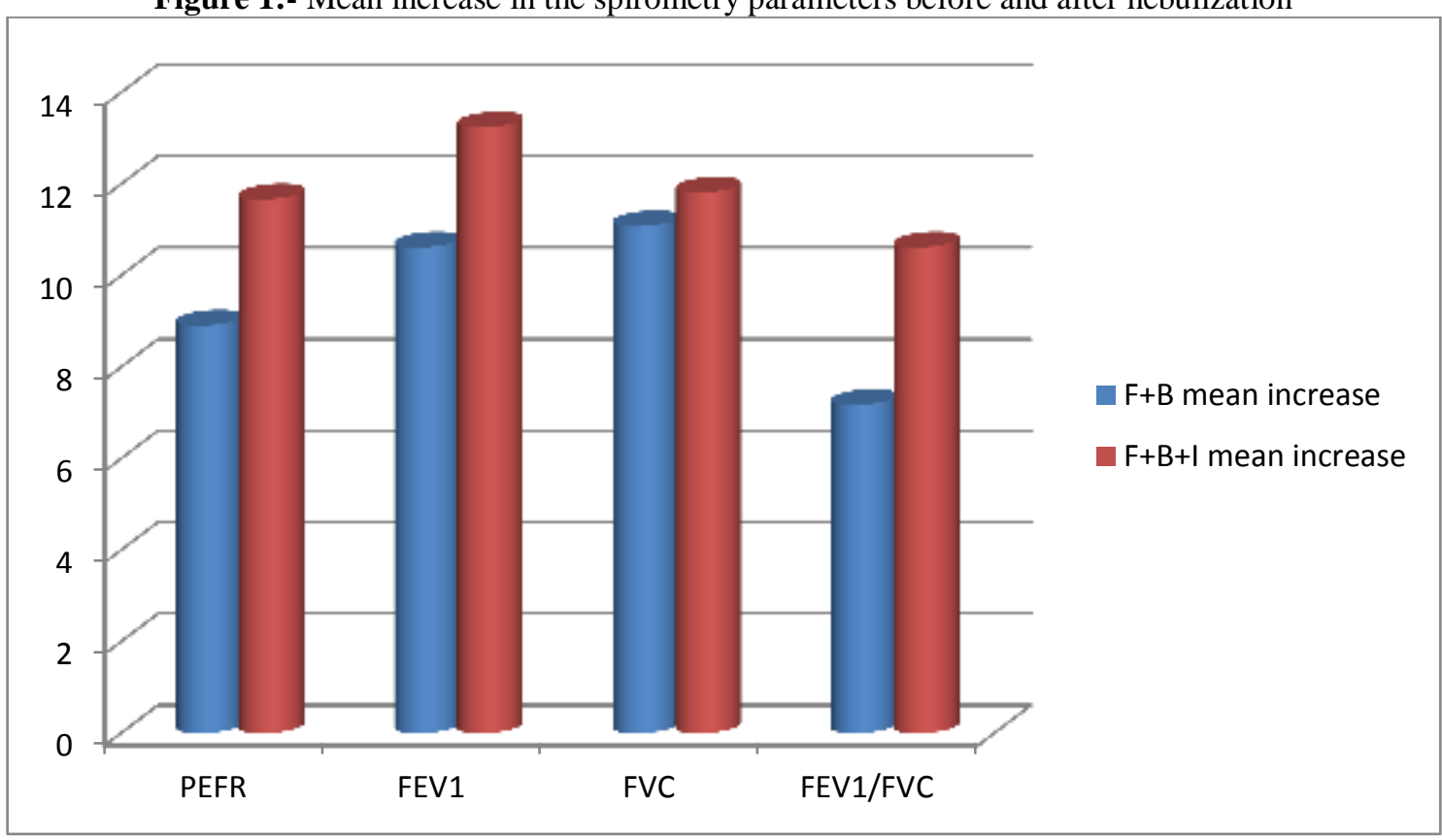

\section{Discussion:-}

With patients becoming increasingly satisfied with nebulized drug delivery, improvement in nebulization equipment, nebulized therapies into the COPD treatment paradigm and availability of domestic, non-invasive nebulization equipment should lead to improved clinical and health economic outcomes for patients with COPD $^{6}$. In the past, physicians have been nebulizing the patients with Formoterol-Budesonide combination during acute attacks as well as during maintenance therapy. Addition of Ipratropium bromide to maintenance therapy has been 
proven to be of benefit but the survey of literature failed to show any study which could substantiate or otherwise refute the beneficial effects of Ipratropium bromide to Formoterol-Budesonide combination.

The study was therefore planned to compare two nebulized treatment regimens one being Formoterol - Budesonide (double drug) \& other Formoterol-Budesonide-Ipratropium bromide (triple drug). It was a prospective, randomized, open label, hospital based study. The efficacy and tolerability of the two nebulized regimen was compared on the basis of the spirometry parameters.

A total of 55 patients were allocated in this study. Out of these, 29 patients were allocated to group 1 and 26 to group 2. Baseline history, current medication, ECG findings, exposure to smoke was compared and no significant difference was obtained in the two groups. This finding proves that the two study groups were comparable.

The results of the study showed that the Spirometry parameters improve post-nebulization in both the groups but the improvement was slightly better in group 2 . Inter-group analysis of post-nebulization parameters was done and no statistically significant difference was found between the two groups. But clinically, the outcome of the patients was better in group 2 post nebulization.

Inter-group comparison of mean increase in the spirometry parameters pre- and post-nebulization was done and it was found that PEFR had statistically significant increase post nebulization in group 2 . This finding indicates that the addition of third drug has some additional benefits.

Aaron et al also showed that addition of third drug (Tiotropium bromide) to LABA/ICS combination indicates that though frequency of exacerbation remains same but the severity of exacerbation was reduced in COPD patients. Triple drug therapy also reduced the rate of hospitalization due to exacerbations, all cause hospitalization. Quality of life and lung function were better with triple drug combination ${ }^{15}$.

There are other studies also showing the additional benefit of adding third drug (LAMA/SAMA) to LABA/ICS combination $^{7-14}$.

The difference in these studies and the present study is that most of these studies were conducted as maintenance triple drug therapy in metered dose inhaler form and for an approximate period of 3 months.

On comparing the present study with the literature, we also found out that triple drug therapy may be more beneficial in metered dose inhaler as it is a long term maintenance therapy. On the other hand, nebulization implements less benefit as it is short term therapy. With nebulization, even the other two drugs (FormoterolBudesonide) have a chance to produce their full spectrum of therapeutic effect because they have time to equilibrate with the blood.

The study conducted by our department was on nebulized triple drug therapy with the single follow-up i.e. after 30 minutes of completion of nebulization. This could be the one reason of not getting statistically significant difference in the post nebulization Spirometry parameters of two groups. But clinical outcome of patients were better in group 2.

The main aim of this study was to look for the additional benefit of anticholinergics to LABA/ICS combination in patients with COPD and it was found that there is additional clinical benefit of adding third drug but the benefit in terms of Spirometry parameters was not statistically significant.

With the current scenario of increasing pollution and smog, the future of the patients with respiratory diseases is difficult. There are wide variations in the population of a particular area therefore frequent studies will be needed to assess the efficacy of the currently available respiratory drugs and their combination. In this study, double drug therapy was compared with triple drug therapy and more studies will be needed to establish the additional benefits of the third drug to a well known combination.

The limitations of the study are less number of the patients in the two groups, current treatment of COPD and recording of single follow up parameters. 
From this study, we concluded that addition of third drug (Ipratropium bromide) during nebulization has some additional advantages but the effects are not very clear from this study. As this was the first study of this kind, the results of this study will serve as baseline. In future we need to design a larger study on more number of patients to establish this fact with frequent follow-up visits.

\section{Declarations:- \\ Funding: Self \\ Conflict of interest: None \\ Ethical approval: Done}

\section{References:-}

1. John J. Reilly, Edwin K. Silverman, Steven D. Shapiro. Chronic Obstructive Pulmonary Disease. In: Anthony S. Fauci, Eugene Braunwald, Dennis L Kasper, Stephen L Hauser, Dan L. Longo, J. Larry Jameson et al. Harrison's Principles of Internal Medicine. $17^{\text {th }}$ ed. New York, NY: Mc Graw-Hill; 2008:1635-42.

2. Philip T Diaz and Daren L Knoell. Chronic Obstructive Pulmonary Disease. In: Kimble Mary Anne Koda, Young Lloyd Yee, Alldredge Brian K, Corelli Robin L, Guglielmo B Joseph, Kradjan Wayne A et al. Applied Therapeutics, The clinical use of drugs. $9^{\text {th }}$ ed. Wolter Kluwer health. 2009; 23: 1-19.

3. P Ravi Kumar, G Priyadarshini Bai, H.V. Suryanarayana. Study of Electrolyte Disturbances in Acute Asthma. Int J Biol Med Res. 2013; 4(3): 3479 - 82.

4. Rabe KF, Atienza T, Magyar P, Larsson P, Jorup C, Lalloo UG. Effect of budesonide in combination with formoterol for reliever therapy in asthma exacerbations: a randomised controlled, double-blind study. Lancet 2006; 368(9537):744-53.

5. Peter J.Barnes. Pulmonary Pharmcology. In: Laurence L Brunton, Bruce A Chabner, Bjorn C Knollman. Goodman \& Gillman's The Pharmacological basis of therapeutics. $12^{\text {th }}$ ed. New York, NY: McGraw-Hill; 2010; $1035-43$.

6. Tashkin P Donald. A review of nebulized drug delivery in COPD. Int J COPD 2016; 11: 2585-96.

7. Brusselle G, Price DB, Gruffydd-Jones K, Miravitlles M, Keininger D, Stewart R et al. The inevitable drift to triple therapy in COPD: an analysis of prescribing pathways in the UK. Int J Chron Obstruct Pulmon Dis 2015; 10: 2207-17.

8. Welte T, Miravitlles M, Hernandez P, Eriksson G, Peterson S, Polanowski T et al. Efficacy and tolerability of budesonide/formoterol added to Tiotropium in patients with chronic obstructive pulmonary disease. Am J Respir Crit Care Med 2009; 180(8): 741-50.

9. Singh D, Brooks J, Hagan G, Cahn A, O’Connor BJ. Superiority of "triple" therapy with Salmeterol/fluticasone propionate and Tiotropium bromide versus individual components in moderate to severe COPD. Thorax 2008; 63(7): 592-8.

10. Jung KS, Park HY, Park SY, Kim SK, Kim YK, Shim JJ et al. Comparison of Tiotropium plus fluticasone propionate/Salmeterol with Tiotropium in COPD: a randomized controlled study. Respir Med 2012; 106(3): $382-9$.

11. Hanania NA, Crater GD, Morris AN, Emmett AH, O'Dell DM, Niewoehner DE. Benefits of adding fluticasone propionate/Salmeterol to Tiotropium in moderate to severe COPD. Respir Med 2012; 106(1): 91 101.

12. Frith PA, Thompson PJ, Ratnavadivel R, Chang CL, Bremner P, Day P et al. Glycopyrronium once-daily significantly improves lung function and health status when combined with Salmeterol/fluticasone in patients with COPD: the GLISTEN study, a randomized controlled trial. Thorax 2015; 70(6): 519-27.

13. Siler TM, Kervin E, Singletary K, Brooks J, Church A. Efficacy and safety of Umeclidinium added to fluticasone propionate/Salmeterol in patients with COPD: Results of two randomized, double blind studies. COPD 2016; 13(1): 1-10.

14. Singh D, Papi A, Corradi M, Pavlisova L, Montagna L, Francisco C et al. Single inhaler triple therapy versus inhaled corticosteroid plus long-acting beta2-agonist therapy for chronic obstructive pulmonary disease (TRILOGY): a double-blind, parallel group, randomized controlled trial. Lancet 2016; 388(10048): 963-73.

15. Aaron SD, Vandemheen KL, Fergusson D, Francols Maltals, Jean Bourbeau, Roger Goldstein et al. Tiotropium in combination with placebo, Salmeterol or fluticasone-salmeterol for treatment of chronic obstructive pulmonary disease: a randomized trial. Ann Intern Med 2007; 146(8): 544-55.

16. Tashkin P Donald. A review of nebulized drug delivery in COPD. Int J COPD 2016; 11: 2585-96.

17. Kikis D, Esser H, Heinrich K. Influence of Ipratropium bromide on Heart rate and Hemodynamics in patients with sinus bradycardia. Clin Cardiol 1982; 5(8): 441-5. 